Jurnal Ekonomi \& Studi Pembangunan

Volume 19, Nomor 1, A pril 2018, hlm. 1-10

DOI: 10.18196/jesp.19.1.3836

\title{
PENGARUH EKSPOR DAN IMPOR TERHADAP PERTUMBUHAN EKONOMI DI INDONESIA
}

\author{
Ismadiyanti Purwaning Astuti, Fitri Juniwati Ayuningtyas \\ Fakultas Ekonomi dan Sosial, Universitas Amikom Yogyakarta \\ Jalan Ring Road Utara, Condong Catur, Depok, Sleman, Yogyakarta, Indonesia, \\ E-mail Korespondensi: ismadiyanti@amikom.ac.id
}

\begin{abstract}
The purpose of this study is to analyze the effect of exports and imports on economic growth in Indonesia in the long term and short term. The data used in this study is secondary data obtained from the World Bank 2000-2016. The analysis used is regression analysis using Error Corection Model (ECM) Method. Tests used in the model are Stationarity Test, R-Square Test, F Test and $T$ Test. The result of this research is that long term, export variable and exchange rate influence to economic growth while import does not have an effect on to economic growth. In the short run, export and import variables affect economic growth, while exchange rates have no effect on economic growth
\end{abstract}

Key Words: export, import, economic growth, ECM

JEL Classification: F10, F14, F17

\section{PENDAHULUAN}

Perkembangan perekonomian suatu negara saat ini tidak dapat terlepas dari kondisi perekonomian global. Hubungan ekonomi antar negara menjadi faktor penting yang berpengaruh terhadap perkembangan ekonomi masing-masing negara. Kondisi ini menyebabkan daya saing sebagai salah satu faktor yang menentukan dalam kompetisi antar negara agar memperoleh manfaat dari semakin terbukanya perekonomian dunia. Keuntungan dari terbukanya perekonomian dunia dapat dilihat dari keadaan neraca pembayaran suatu negara.

Menurut Bank Indonesia, neraca pembayaran merupakan catatan transaksi ekonomi antara penduduk Indonesia dengan bukan penduduk pada suatu periode tertentu. Neraca pembayaran sebuah negara dikatakan surplus apabila terdapat kelebihan dana perdagangan dan investasi dibandingkan kewajiban-kewajiban yang dibayarkan kepada negara sedangkan dikatakan defisit apabila impor lebih besar dari pada ekspor. Keadaan neraca pembayaran yang surplus atau defisit mempengaruhi pertumbuhan ekonomi Indonesia.

Hubungan antara perdagangan internasional dan pertumbuhan ekonomi menjadi topik yang banyak di bahas di bidang ekonomi tetapi masih kontroversial. Kemunculan literature mengenai pertumbuhan endogen memungkinkan peran yang lebih besar dari keterbukaan eksternal negara-negara dalam proses perkembangan teknologi dibandingkan dengan model pertumbuhan Solow yang tradisional. Pendekatan baru ini menekankan bahwa inovasi teknologi muncul sebagai respon terhadap insentif ekonomi dimana lingkungan kelembagaan, hukum, keterbukaan dan integrasi ekonomi mempengaruhi kecepatan dan arah perubahan teknologi (Grossman dan Helpman, 1994; Aghion dan Howitt, 1998).

Di sisi lain, banyak literatur empiris yang menunjukkan bahwa perdagangan internasional dan kebijakan perdagangan yang lebih terbuka merupakan faktor utama untuk menjelaskan pertumbuhan ekonomi. Negara dengan sikap 
perdagangan yang lebih liberal memungkinkan menikmati jumlah input liberal lebih tinggi dengan biaya yang lebih rendah sehingga menghasilkan pertumbuhan yang lebih tinggi (Edwards, 1992 dan 1993).

Menurut Thirlwall (1979), neraca pembayaran bertindak sebagai kendala pada tingkat pertumbuhan output. Kenaikan output domestik karena meningkatnya impor dapat menyebabkan defisit neraca pembayaran yang memungkinkan penurunan permintaan atau depresiasi nilai tukar riil. Negara-negara tumbuh lebih cepat dalam menghadapi elastisitas pendapatan yang lebih tinggi untuk ekspor daripada impor. Hal ini disebabkan tidak ada negara yang pertumbuhannya lebih cepat daripada tingkat pembayaran yang harus dibayar karena rasio utang luar negeri terhadap PDB yang besar menyebabkan keruntuhan kepercayaan internasional dan eksternal.

Defisit neraca berjalan yang tinggi tidak menjadi masalah bila anggaran pemerintah seimbang dan keputusan penghematan dan investasi diambil secara optimal oleh agen swasta (Corden, 2007). Namun menurut Edward (2002), defisit eksternal harus menjadi perhatian dalam menerapkan kebijakan bahkan jika defisit akun berjalan tidak mengarah pada krisis mata uang. Dengan kata lain bukan pada seberapa besar defisitnya tetapi bagaimana negara menjalankan defisit yang tidak berkelanjutan. Secara umum, defisit transaksi berjalan yang tidak melebihi 5\% dari PDB dianggap tidak berkelanjutan sehingga diatas ambang ini mulai dilakukan proses penyesuaian (Freund, 2005).

Penelitian sebelumnya yang dilakukan oleh Bajo-Rubio (2012) meneliti mengenai neraca pembayaran yang bertindak sebagai kendala pada tingkat pertumbuhan di Spanyol. Data yang digunakan data time series selama periode 18502000. Pada jangka panjang, defisit eksternal tidak bekerja sebagai kendala pertumbuhan ekonomi tetapi bekerja pada sub periode 1940-1959 dan 1959-1974. Perekonomian Spanyol menggunakan defisit eksternal untuk memperlancar tingkat konsumsi agregat yang didukung oleh keberlanjutan defisit transaksi sepanjang periode analisis.

Atilla dan Erhan (2013) meneliti penerapan model Thirlwall pada keseimbangan neraca pembayaran untuk ekonomi Turki pada periode 19682011. Penelitian ini juga mengevaluasi prosedur pengujian prinsip Thrilwall dengan memperkirakan elastisitas pendapatan pada permintaan impor dengan menggunakan metode stasioneritas dan kointegrasi. Dengan menggunakan analisis kointegrasi johansen antara PDB dan ekspor mempunyai hubungan positif secara statistik signifikan. Temuan ini membuktikan bahwa model pertumbuhan keseimbangan Thirlwall berlaku untuk ekonomi Turki.

Penelitian yang dilakukan oleh Elias, Pedro dan Mocaela (2014), menerapakan model SCA di Italis dan memeriksa ketepatan untuk menjelaskan jalur pertumbuhan negara. Italia merupakan kasus yang menarik mengenai karena dalam decade terakhir menghadapi ketidakseimbangan internal yang disebabkan oleh defisit dan hutang publik yang tinggi. Hasil dari penelitian ini menunjukkan bahwa Italia tumbuh dengn lebih lambat dari kapasitas pontensinya karena kendala pasokan. Kebijakan untuk meningkatkan daya saing eksternal dan menurunkan biaya ekonomi terbukti efektif untuk mencapai pertumbuhan yang lebih tinggi.

Penelitian ini meneliti bagaimana neraca pembayaran mempengaruhi pertumbuhan ekonomi yang dianalisis dari sisi neraca berjalan dalam NPI. Sisi neraca berjalan yang diteliti adalah mengenai ekspor, impor dan nilai tukar. Berdasarkan model yang dikembangkan oleh Thirlwall (1979), penelitian ini meneliti pengaruh neraca pembayaran terhadap pertumbuhan ekonomi dalam jangka pendek dan jangka pan- 
jang mengunakan analisis regresi berganda dengan metode ECM. Jangka pendek yang digunakan dalam penelitian ini adalah kurang dari 5 tahun sedangan jangka panjang lebih dari 5 tahun.

\section{METODE PENELITIAN}

Data dan Sumber Data

Penelitian ini menggunakan metode pendekatan yang bersifat kuantitatif. Menurut Sugiono (2016), metode kuantitatif adalah pendekatan ilmiah yang memandang suatu realitas itu dapat diklasifikasikan, konkrit, teramati dan terukur, hubungan variabel bersifat sebab akibat dimana data penelitiannya berupa angka-angka. Dalam penelitian ini memfokuskan pada penjelasan hubungan antara neraca pembayaran sebagai variabel dependen dan pertumbuhan ekonomi sebagai variabel independen di Indonesia dengan menggunakan data runtut waktu (time series) dari tahun 1967-2016. Jenis data yang digunakan dalam penelitian ini adalah data sekunder. Data tersebut diperoleh dari World Bank.

\section{Definisi Operasional variabel}

Variabel ini dikelompokkan menjadi 2(dua) yaitu variabel dependen (variable terikat) dan variabel independen (variable bebas). Variabel dependen yang digunakan dalam penelitian ini adalah pertumbuhan ekonomi sedangkan variabel independen yang digunakan adalah ekspor, impor dan tingkat kurs. Definisi variabel yang digunakan dalam penelitian ini adalah: pertama, Gross Domestik Produk (GDP) adalah jumlah nilai bruto yang ditambahkan oleh seluruh produsen dalam perekonomian yang ditambah pajak dan dikurangi subsidi yang tidak termasuk dalam nilai suatu produk. Penelitian ini menggunakan prosentase tingkat pertumbuhan GDP tahunan pada harga pasar berdasarkan pada mata uang Indonesia yang konstan. Data pertumbuhan GDP harga konstan di ambil dari The World Bank. Kedua, ekspor (EKS) adalah proses penjualan ba- rang atau komoditas dari suatu negara ke negara lain. Ekspor yang digunakan dalam penelitian ini adalah ekspor barang dan jaas yang mewakili nilai semua barang dan layanan pasar lainnya yang diberikan ke seluruh dunia. Layanan tersebut termasuk nilai barang dagangan, kargo, asuransi, transportasi, perjalanan, royalty, biaya lisensi dan layanan lainnya seperti layanan komunikasi, konstruksi, keuangan, informasi, bisnis, pribadi, dan pemerintah. Data dalam dolar A.S.

Ketiga, impor (IMP) adalah kegiatan memasukkan barang dari luar negeri ke dalam negeri. Impor yang digunakan dalam penelitian ini adalah impor barang dan jasa yang mewakili nilai semua barang dan layanan pasar lainnya yang diterima dari negera-negara lain di dunia. Layanan tersebut termasuk nilai barang dagangan, kargo, asuransi, transportasi, perjalanan, royalty, biaya lisensi dan layanan lainnya seperti layanan komunikasi, konstruksi, keuangan, informasi, bisnis, probadi dan pemerintah. Data impor yang digunakan dalam dolar A.S. Keempat, kurs (KURS) adalah harga sebuah mata uang dari suatu negara yang diukur atau dinyatakan dalam mata uang lainnya. Kurs yang digunakan dalam penelitian ini adalah nilai tukar/ kurs resmi yang mengacu pada nilai tukar yang ditentukan oleh otoritas nasional atau tingkat suku bunga yang ditentukan di pasar bursa yang disetujui secara hukum. Kurs ini dihitung sebagai rata-rata tahunan berdasarkan rata-rata bulanan (mata uang local yang relative terhadap dolar A.S).

\section{Alat Analisis}

Dalam penelitian ini untuk menjawab permasalahan maka model yang digunakan pada data time series ini adalah model koreksi kesalahan atau ECM ( Error Correction Model) dengan syarat utama bahwa data tidak stasioner di tingkat level, tetapi stasioner pada derajat integrasi dan variabelnya terkointegrasi. Model yang digunakan untuk melakukan koreksi ketid- 
akseimbangan jangka pendek menuju jangka panjang. Dan model regresi berganda menggunakan
Ordinary Least Square (OLS). Model yang digunakan adalah sebagai berikut:

Model umum dari regresi berganda yaitu:

$$
Y t=a 0+a 1 X t+\varepsilon t \text {. }
$$

Model umum Error Correction Model (ECM) yaitu:

$$
\Delta \mathrm{Yt}=\mathrm{a} 0+\mathrm{a} 1 \Delta \mathrm{Xt}-1+\mathrm{a} 2 \Delta \mathrm{ECt}-1+\varepsilon \mathrm{t} .
$$

Model regresi berganda Ordinary Least Square (OLS) yaitu:

$$
\text { GDPt }=a 0+a 1 \text { LOG_EKSt }+ \text { a3 LOG_IMPt }+ \text { a3LOG_KURSt }+\varepsilon t .
$$

Model Error Correction Model (ECM) yaitu:

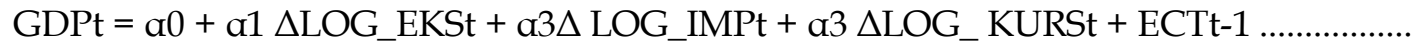

Dimana:

$\begin{array}{ll}\text { GDPt } & =\text { Pertumbuhan Ekonomi; } \\ \text { LOG_EKSt } & =\text { Ekspor rill; } \\ \text { LOG_IMPt } & =\text { Impor riil; } \\ \text { LOG_KURSt } & =\text { Nilai Tukar; } \\ \mathrm{a} 0 & =\text { konstanta; } \\ \mathrm{a} 1, \mathrm{a} 2, \mathrm{a} 3 & =\text { koefisien; } \\ \text { ct } & =\text { Error term; } \\ \text { ECTt-1 } & =\text { Error Correction Term }\end{array}$

Analisis yang digunakan dalam penelitian ini adalah metode analisis deskriptif kuantitatif dengan menggunakan teori-teori dan data-data yang berhubungan dengan penelitian ini. Analisis data digunakan untuk menyederhanakan data yang telah diperoleh ke dalam bentuk yang lebih mudah dibaca dan diinterpretasikan. Pada penelitian ini, dalam menganalisis data menggunakan menggunakan software Microsoft Excel 2007 dan kemudian diolah menggunakan EViews 7. Hal ini dilakukan agar hasil yang diperoleh lebih dapat telihat perbedaan pengaruh antara masing-masing variabel terhadap Keseimbangan Primer. Tahapan analisis data dalam penelitian ini dilakukan melalui beberapa tahap yaitu: pertama, Uji Stasioneritas (Uji Akar Unit), Uji stasioneritas ini bertujuan untuk mengetahui apakah data runtut waktu yang digunakan sudah stasioner atau belum. Regresi palsu (spurious regression) dihasilkan jika data tidak stasioner.

Dalam penelitian pada dasarnya data runtut waktu sering mengalami ketidak stasioneran pa- da level series. Sehingga perlu dilakukannya differensiasi satu atau dua kali untuk menghasilkan data satsioner. Untuk mengetahui apakah data runtut waktu yang digunakan stasioner atau tidak stasioner, salah satu cara yang dapat dilakukan adalah menggunakan uji akar unit (unit roots test). Uji akar unit dilakukan dengan menggunakan metode Augmented H1: tidak terdapat akar unit (data stasioner), H0: terdapat akar unit (data tidak stasioner) Dicky Fuller (ADF), dengan hipotesis sebagai berikut: Hasil statistik dari hasil estimasi pada metode ADF akan dibandingkan dengan nilai kritis McKinnon pada titik kritis $1 \%$, 5\%, dan $10 \%$. Jika nilai t-statistik lebih kecil dari nilai kritis McKinnon maka H0 diterima, artinya data terdapat akar unit atau data tidak stasioner. Jika nilai t-statistik lebih besar dari nilai kritis McKinnon maka H0 ditolak, artinya data tidak terdapat akar unit atau data stasioner.

Kedua, Kointegrasi merupakan suatu hubungan jangka panjang antara variabel-variabel 
yang meskipun secara individual tidak stasioner, tetapi kombinasi linier antara variabel tersebut dapat menjadi stasioner. Keadaan variabel yang tidak stasioner menyebakan kemungkinan adanya hubungan jangka panjang antara variabel dalam sistem ECM. Salah satu syarat agar tercapai keseimbangan jangka panjang adalah galat keseimbangan harus berfluktuasi di sekitar nol. Dengan kata lain, error term harus menjadi sebuah data runtut waktu yang stasioner. Tujuan adanya uji kointegrasi ini adalah agar seluruh variabel terintegrasi pada tingkat yang sama. Ada beberapa metode yang dapat digunakan untuk melakukan uji kointegrasi (Enders, 1995).

Ketiga, teknik untuk mengoreksi ketidakseimbangan jangka pendek menuju keseimbangan jangka panjang disebut dengan Error Correction Model (ECM), yang dikenalkan oleh Sargan dan dipopulerkan oleh Engle-Granger. Model ECM pada umumnya merupakan suatu konsep model ekonometris runtut waktu yang bertujuan untuk menyeimbangkan kondisi jangka pendek dengan kondisi jangka keseimbangan jangka panjang melalui suatu proses penyesuaian.

Engle and Granger (1987) mengemukakan bahwa apabila diantara sejumlah peubah terdapat kointegrasi, maka diperoleh kondisi yang disebut error correction repsensentation yang mengindikasikan bahwa perubahan yang terjadi terhadap variabel terikat tidak hanya dipengaruhi oleh var- iabel bebas tetapi juga dipengaruhi oleh keseimbangan dari hubungan kointegrasi. Ketidakseimbangan dari hubungan kointegrasi ini ditunjukan oleh nilai error-correction term. Selain itu dalam ekonometrika ECM berguna dalam mengatasi masalah data time series yang tidak stasioner dan masalah spurious regression. Analisis dengan menggunakan ECM melalui 3 langkah analisis data yaitu (1) uji stasioner data, (2) uji kointegrasi untuk mengetahui apakah terdapat hubungan jangka panjang antara variabel $\mathrm{X}$ dengan $\mathrm{Y}$, dan (3) menyusun Error-Correction Model (Gujarati, 2009).

\section{HASIL DAN PEMBAHASAN}

Dalam menganalisis hasil estimasi model ECM dalam jangka panjang dan jangka pendek sebelumnya dilakukan pengujian data. Data yang digunakan dalam penelitian perlu diuji menggunakan dua uji stasioneritas data yaitu uji akar-akar unit dan uji kointegrasi. Pengujian stasioneritas data yang dilakukan terhadap seluruh variabel dalam modell penelitian didasarkan pada Augmented Dickey Fuller (ADF) Test, yang perhitungannya menggunakan bantuan komputer dengan program EViews 7. Pengujian akarakar unit dilakukan dengan memasukkan intersep namun tidak memasukkan trend waktu pada uji DF, dan dengan memasukkan intersep dan trend waktu pada uji ADF.

Tabel 1. Hasil Uji Akar-akar unit dengan Augmented Dickey-Fuller test pada Level

\begin{tabular}{cccccc}
\hline ADF Statistik & Tanda & Nilai Kritis 1\% & Nilai Kritis 5\% & Nilai Kritis 10\% & Keterangan \\
\hline Variabel GDP & & & & & \\
\hline-6.751397 & $<$ & -3.577723 & -2.925169 & -2.600658 & Stasioner \\
\hline Variabel Ekspor & & & & & \\
\hline 0.807999 & $>$ & -3.571310 & -2.922499 & -2.599224 & Tidak Stasioner \\
\hline Variabel Impor & & & & -2.599224 & Tidak Stasioner \\
\hline-0.058198 & $>$ & -3.571310 & -2.922449 & & \\
\hline Variabel Kurs & & & & -2.599224 & Tidak Stasioner \\
\hline-0.073768 & $>$ & -3.571310 & -2.922449 & & \\
\hline
\end{tabular}

Sumber: Eviews 7

Pengaruh Ekspor Dan Impor Terhadap Pertumbuhan... (Ismadiyanti P. Astuti, Fitri J. Ayuningtyas) 
Berdasarkan tabel 1, maka diketahui sebagian besar variable tidak stasioner pada derajat level. Hanya variable GDP yang stasioner sedangkan variable ekspor, impor dan kurs tidak stasioner. Oleh karena itu, untuk keperluan regresi ECM maka perlu dilakukan proses diferensi terhadap data tersebut agar data stasioner pada derajat yang sama. Dengan prosedur yang sama seperti langkah di atas maka hasil uji akar-akar unit Augmented Dickey Fuller (ADF) test pada derajat first difference sebagai berikut:

Tabel 2. Hasil Uji Akar-akar unit dengan Augmented Dickey-Fuller test pada First Different

\begin{tabular}{cccccl}
\hline ADF Statistik & Tanda & Nilai Kritis 1\% & Nilai Kritis 5\% & Nilai Kritis 10\% & Keterangan \\
\hline Variabel GDP & & & & & \\
\hline-7.900274 & $<$ & -3.592462 & -2.931404 & -2.603944 & Stasioner \\
\hline Variabel Ekspor & & & & \\
\hline-7.475822 & $<$ & -3.574446 & -2.923780 & -2.599925 & Stasioner \\
\hline Variabel Impor & & & & \\
\hline-5.75339 & $<$ & -3.574446 & -2.923780 & -2.599925 & Stasioner \\
\hline Variabel Kurs & & & & \\
\hline-8.176376 & $<$ & -3.574446 & -2.923780 & -2.599925 & Stasioner \\
\hline
\end{tabular}

Sumber: Eviews 7

Hasil uji akar-akar unit Augmented Dickey Fuller (ADF) test pada derajat first difference menunjukkan bahwa semua data telah stasioner pada derajat yang sama yaitu first difference.

Setelah uji stasioneritas melalui uji akarakar unit dan derajat integrasi pada first difference terpenuhi, maka langkah selanjutnya adalah melakukan uji kointegrasi untuk mengetahui pa- rameter jangka panjang. Uji statistik yang sering dipakai adalah uji CRDW, uji DF dan uji ADF. Dalam penelitian ini yang digunakan untuk menguji kointegrasi adalah dengan uji Augmented Dickey Fuller (ADF). Uji ADF untuk melihat apakah residual regresii kointegrasi stasioner atau tidak.

Tabel 3. Hasil uji akar-akar unit terhadap residual dengan ADF test

\begin{tabular}{lrrr}
\hline & & t-Statistic & Prob. $^{*}$ \\
\hline Augmented Dickey-Fuller test statistic & -7.878186 & 0.0000 \\
Test critical values: & 1\% level & -3.577723 & \\
& 5\% level & -2.925169 & \\
& $10 \%$ level & -2.600658 & \\
\hline
\end{tabular}

Sumber: Eviews 7

Berdasarkan uji ADF tersebut diketaui bahwa residual pada persamaan jangka panjang sudah stasioner pada derajat level karena ADF statistic secara absolute lebih besar dari pada critical value baik pada $1 \%, 5 \%$ maupun $10 \%$ atau dilihat dari probabalitasnya adalah 0.0000 . Hal ini berarti residual tidak mengandung akar-akar unit sehingga pemodelan ECM menjadi terpenuhi. Hasil model ECM dalam jangka panjang diestimasi menggunakan regresi OLS dengan eviews. Hasilnya ditunjukkan sebagai berikut: 
Tabel 4. Hasil Estimasi Model ECM dalam Jangka Panjang

\begin{tabular}{lcccc}
\hline \multicolumn{1}{c}{ Variable } & Coefficient & Std. Error & t-Statistic & Prob. \\
\hline C & -63.07803 & 22.67858 & -2.781393 & 0.0079 \\
LOG_EKS & 4.323007 & 1.426257 & 3.031016 & 0.0040 \\
LOG_IMP & -0.976283 & 0.608031 & -1.605646 & 0.1153 \\
LOG_KURS & -1.967722 & 0.555363 & -3.543127 & 0.0009 \\
R-squared & 0.284638 & & & \\
Adjusted R-squared & 0.236948 & & & \\
F-statistic & 5.968418 & & & \\
Prob(F-statistic) & 0.001627 & & & \\
\hline
\end{tabular}

Sumber: Eviews 7

Tabel 4 merupakan hasil estimasi OLS dengan menggunakan model ECM dalam jangka panjang. Hasil regresi tersebut untuk mengetahui hubungan antara variabel dependen dan variabel independen. Variabel dependen yang digunakan adalah tingkat pertumbuhan ekonomi (GDP) sedangkan Variabel independen yang digunakan adalah jumlah ekspor, jumlah impor dan kurs rupiah terhadap dolar Amerika. Nilai adjusted Rsquared sebesar 0.236948 menjelaskan bahwa variabel independen di dalam model dapat menjelaskan variasi variabel dependen sebesar 23, 6948 persen. Nilai F-statistik sebesar 5.968418 menunjukkan bahwa variabel independen dalam jangka panjang seperti ekspor, impor dan kurs berpengaruh secara bersama-sama terhadap tingkat pertumbuhan ekonomi.

Dengan menggunakan tingkat signifikansi $1 \%$, dapat dianalisis ada dua variabel yang signifikan yaitu jumlah ekspor dan tingkat kurs rupiah sedangkan variabel impor tidak signifikan. Hal tersebut dapat disimpulkan dalam jangka panjang, jumlah ekspor dan tingkat kurs rupiah berpengaruh signifikan terhadap pertumbuhan ekonomi sedangkan jumlah impor tidak berpengaruh signifikan terhadap pertumbuhan ekonomi. Jumlah impor meningkat atau menurun tidak berpengaruh terhadap pertumbuhan ekonomi.

Dari hasil regresi dapat dilihat bahwa jumlah ekspor berpengaruh positif dan signifikan

terhadap pertumbuhan ekonomi. Jumlah ekspor meningkat sebesar 1 persen maka akan meningkatkan pertumbuhan ekonomi sebesar 4.323007 persen. Apabila jumlah ekspor menurun sebesar 1 persen maka akan menurunkan pertumbuhan ekonomi sebesar 4,323 persen Hal tersebut sejalan dengan teori perdagangan internasional, apabila jumlah barang atau jasa yang di ekspor ke luar negeri semakin banyak maka di dalam negeri harus memproduksi barang dan jasa lebih banyak juga. Semakin banyak barang yang di ekspor ke luar negeri maka arus modal yang masuk ke dalam negeri juga dalam jumlah yang banyak. Arus modal masuk tersebut yang akan dikelola melalui pendanaan modal untuk usaha besar, kecil dan menengah. Hal tersebut akan meningkatkan jumlah output baik barang dan jasa yang akan meningkatkan pertumbuhan ekonomi dalam jangka panjang.

Tingkat kurs rupiah berpengaruh negative terhadap pertumbuhan ekonomi dan signifikan. Apabila tingkat kurs rupiah meningkat (depresiasi) sebesar 1 persen maka akan menurunkan tingkat pertumbuhan ekonomi sebesar 1.967722 persen. Sedangkan tingkat kurs rupiah menurun (apresiasi) sebesar 1 persen maka akan menaikkan tingkat pertumbuhan ekonomi sebesar 1,977 persen. Apabila nilai tukar terdepresiasi atau nilai uang dalam negeri menurun maka barang yang diimpor harganya akan naik. Kenaikan barang impor akan menaikkan barang produksi 
yang diimpor dari luar negeri sehingga produktifitas dalam negeri semakin menurun yang akan menurunkan pertumbuhan ekonomi dalam negeri.
Hasil estimasi Model Koreksi Kesalahan (ECM) dalam jangka pendek ditunjukkan oleh hasil di bawah ini:

Tabel 5. Hasil Estimasi Model ECM Jangka Pendek

\begin{tabular}{lcccc}
\hline \multicolumn{1}{c}{ Variable } & Coefficient & Std. Error & t-Statistic & Prob. \\
\hline C & -0.666708 & 0.320740 & -2.078655 & 0.0438 \\
D(LOG_EKS) & 6.344579 & 2.565819 & 2.472731 & 0.0175 \\
D(LOG_IMP) & 2.895370 & 1.459956 & 1.983190 & 0.0539 \\
D(LOG_KURS) & 1.651570 & 1.789498 & 0.922924 & 0.3613 \\
ECT & -1.036208 & 0.146975 & -7.050228 & 0.0000 \\
R-squared & 0.691479 & & & \\
Adjusted R-squared & 0.662096 & & & \\
F-statistic & 23.53329 & & & \\
Prob(F-statistic) & 0.000000 & & & \\
\hline
\end{tabular}

Sumber: eviews 7

Hasil estimasi tabel 5 didapat koefisien variabel ECT (Error Correction Term) yaitu sebesar 1.036208 yang mempunyai makna bahwa perbedaan antara tingkat pertumbuhan dengan nilai keseimbangannya akan disesuaikan dalam waktu 1 tahun. Koefisien ECT ini digunakan untuk mengukur respon regressand setiap periode yang menyimpang dari keseimbangan. Menurut Widarjono (2009), koefisien ECT dalam bentuk nilai absolute menjelaskan seberapa cepat waktu yang diperlukan untuk mendapatkan nilai keseimbangan. Nilai ECT sebesar -1.036208 dengan probabilitas 0.0000 yang berarti signifikan pada tingkat signifikansi 1 persen sehingga model ECM dalam jangka pendek adalah valid atau cukup baik.

Nilai adjusted R2 sebesar 0.662096 yang mempunyai arti bahwa sebesar 66, 21 persen variasi variabel pertumbuhan ekonomi secara bersama-sama dapat dijelaskan oleh variabel bebas yang terdiri dari ekspor, impor dan tingkat kurs. Sedangkan sisanya sebesar 33.79 persen dijelaskan oleh variabel-variabel lain di luar model. Nilai F-statistik sebesar 23.53329 menunjukkan bahwa variabel independen seperti ekspor, impor dan kurs secara bersama-sama berpengaruh terhadap tingkat pertumbuhan ekonomi.

Dua variabel tersebut adalah variabel ekspor yang signifikan pada tingkat signifikansi 5 persen dan impor juga signifikan pada tingkat signifikansi 10 persen, sedangkan kurs tidak signifikan pada jangka pendek. Kurs dalam jangka pendek atau kurang dari lima tahun tidak mempunyai pengaruh terhadap pertumbuhan ekonomi. Tingkat kurs yang meningkat atau menurun tidak berpengaruh terhadap pertumbuhan ekonomi.

Ekspor berpengaruh positif dan signifikan terhadap pertumbuhan ekonomi dalam jangka pendek. Koefisien ekspor sebesar 6.344579 berarti apabila ekspor meningkat 1 persen maka akan meningkatkan pertumbuhan ekonomi sebesar 6,344 persen dan apabila ekspor menurun sebesar 1 persen maka akan menurunkan pertumbuhan ekonomi sebesar 6,344 persen. Ekspor yang meningkat akan mendorong peningkatan produksi dalam negeri. Produksi yang meningkat akan menggerakkan roda perekonomian dalam negeri sehingga pertumbuhan ekonomi meningkat. 
Impor berpengaruh positif dan signifikan terhadap pertumbuhan ekonomi. Koefisien impor sebesar 2.895370 berarti apabila impor meningkat 1 persen maka akan meningkatkan pertumbuhan ekonomi sebesar 2,895 persen dan apabila impor menurun sebesar 1 persen maka akan menurunkan pertumbuhan ekonomi sebesar 2,895 persen. Barang dan jasa yang digunakan untuk memenuhi kebutuhan masyarakat dan sebagai bahan baku produksi banyak yang diimpor dari negara lain. Apabila barang dan jasa yang diimpor dari luar negeri meningkat maka akan mendorong peningkatan kegiatan perekonomian dalam negeri baik produksi, konsumsi dan distribusi. Jika kegiatan perekonomian berjalan dengan baik maka akan meningkatkan pertumbuhan ekonomi.

\section{SIMPULAN}

Kesimpulan yang dapat diambil dari penelitian ini bahwa Dalam jangka panjang, jumlah ekspor dan tingkat kurs rupiah berpengaruh signifikan terhadap pertumbuhan ekonomi sedangkan jumlah impor tidak berpengaruh signifikan terhadap pertumbuhan ekonomi. Hal tersebut sejalan dengan teori perdagangan internasional, apabila jumlah barang atau jasa yang di ekspor ke luar negeri semakin banyak maka di dalam negeri harus memproduksi barang dan jasa lebih banyak juga. Kenaikan barang impor akan menaikkan barang produksi yang diimpor dari luar negeri sehingga produktifitas dalam negeri semakin menurun yang akan menurunkan pertumbuhan ekonomi dalam negeri.

Dalam jangka pendek terdapat dua variabel yang yang signifikan. Dua variabel tersebut adalah variabel ekspor yang signifikan pada tingkat signifikansi 5 persen dan impor juga signifikan pada tingkat signifikansi 10 persen, sedangkan kurs tidak signifikan pada jangka pendek. Ekspor yang meningkat akan mendorong peningkatan produksi dalam negeri. Produksi yang meningkat akan menggerakkan roda perekonomian dalam negeri sehingga pertumbuhan ekonomi meningkat. Apabila barang dan jasa yang diimpor dari luar negeri meningkat maka akan mendorong peningkatan kegiatan perekonomian dalam negeri baik produksi, konsumsi dan distribusi. Jika kegiatan perekonomian berjalan dengan baik maka akan meningkatkan pertumbuhan ekonomi.

\section{DAFTAR PUSTAKA}

Aliman. (2000). Modul Ekonometrika Terapan. Yogyakarta: PAU Studi Ekonomi UGM.

Aghion P. dan Howitt P. (1998). Endogenous Growth Theory. Cambridge: The MIT Presss.

Atilla Gokce dan Erhan Cankal. (2013). Balanceof-payments constrained growth model for the Turkish economy.

Bajo-Rubio, Oscar. (2012). The balance-ofpayments constraint on economic growth in a long-term perpective: Spain, 1850-2000. Exploration in Economic History, vol. 49: 105-117.

Edwards S. (1992). Trade Orientation, Distortions and Growth in Developing Countries. Journal of Development Economics, Vol.39: 3157.

Edwards S. (1993). Openness, Trade Liberalization, and Growth in Developing Countries. Journal of Economic Literature Vol. 31: 1358-1393.

Elias Soukiazis, Pedro Andre Cerqueira dan Micaela Antunes. (2014). Explaining Italy's economic growth: A balance-of-payment approach with internal dan external imbalance and non-neutral relative price. Economic Modelling Vol.40: 334-341.

Freund C. (2005). Current Account Adjusment in Industrial Countries. Journal of International Money and Finance Vol. 24: 1278-1298.

Grossman, G.M. dan Helpman, E. (1994). Endogenous Innovation in the Theory of Growth. 
Journal of Perspectives, Vol.8: 23-44.

Holland, Marcio, Flavio Vieire dan Otaviano Canuto. (2004). Economic Growth and the Balance-of-Payment Constraint in Latin America. Investigacion Economica, Vol.63 No.247: 45-74.

Mankiw, N.Gregory. (2003). Teori Makroekonomi. Jakarta: Penerbit Erlangga.

Mccombie dan Thirlwall. (1994). Economic Growth and the Balance of Payment Constraint. London: MacMilan.

Razmi, Arslan. (2005). Balance-of-paymentconstrained growth model: the case of India, Vol.27 No. 4: 655-687.

Reksoprayiitno, Soedijono. (2002). Ekonomi Keuangan Internasional. Yogyakarta: UPP AMP YKPN.

Sugiyono. (2016). Metode Penelitian Kuantitatif, Kualitatif dan R\&D. Bandung: Alfabeta.

Thirlwall. (1979). The balance of payments constraint as an explanation of international growth rate differences. Banca Nazionale del Lavoro, Quarterly Review: 45-53

Widarjono, Agus. (2009). Ekonometrika: Pengantar dan Aplikasinya. Yogyakarta: Penerbit ekonisia FE UII. 